\title{
Sattwa, Rajas \& Tamas (SRT) Factors in Depression
}

\author{
K V. AnoopKumar ${ }^{1 *}$, Late Dr. J P. Balodhi ${ }^{2}$
}

\section{ABSTRACT}

The Bhagavad Gita embodies a bouquet of beautiful flowers of spiritual truths collected from the Upanishads. Many a times it has being misunderstood solely as a religious text and the sheer amount of psychotherapeutic concepts embodied in it has been neglected. The present study throws light on the concept of "Gunas" the basic personality attributes according to Indian philosophy that to a great extend determines the total behaviour patterns, and is referred to throughout in Gita. An attempt has been made through this explorative work to find out which of the three Gunas; Sattwa, Rajas and Tamas is predominant in patients diagnosed with depression. For this purpose a sample or 20 patients diagnosed with mild to moderate depression (ICD-10 criteria for depression) was selected from various adult psychiatric units and outpatient department of NIMHANS after screening them for current level of depression using the Beck's Depression Inventory. A sample of 20 cases of normal was randomly selected from the general population using GHQ as the screening instrument. The age group included was 18-65 years with minimum educational qualification of $7^{\text {th }}$ standard and with ability to read and comprehend English. Patients having a history of any organic conditions, protracted physical illness and psychotic illness were excluded from the study. Purposive random sampling was used to collect the sample. The SRT inventory was administered to the selected mild to moderate depressed patients and the sample of normals, and the 'Triguna' scores were obtained. Statistical measures like percentages, mean, standard deviation, t-test and correlations were employed to undertake a with-in group and between group analyses of the data obtained. The results of the study shows that the clinical population is predominantly Rajasic compared to the predominantly Sattwic disposition of the normal population.

Keywords: Bhagavad Gita, Gunas, Depression, SRT Inventory

\section{TRIGUNA THEORY- An Indian Approach to Personality}

The Sanskrit word guna (guna) has the basic meaning of "string" or "a single thread or strand of a cord or twine". In more abstract uses, it may mean "a subdivision, species, kind, and generally,

${ }^{1}$ Clinical Psychologist, Government mental health Centre, Kozhikode, Kerala (India)

${ }^{2}$ Professor, Department of clinical Psychology, NIMHANS, Bangalore (India)

*Responding Author

(C) 2016 I A Kumar, J Balodhi; licensee IJIP. This is an Open Access Research distributed under the terms of the Creative Commons Attribution License (http://creativecommons.org/licenses/by/2.0), which permits unrestricted use, distribution, and reproduction in any Medium, provided the original work is properly cited. 


\section{Sattwa, Rajas \& Tamas (SRT) Factors in Depression}

quality. In Classical literature (e.g. Mahabharata, Bhagavata Purana and Bhagavad Gita), a Guna is an attribute of the 5 elements each with an associated organ (Sri Aurobindo, 1942):

1. Ether which has sound (shabda) for its Guna (and the ear for its organ). Aether (also spelled ether) is a concept used in ancient and medieval science as a substance. The aether was believed to be the substance which filled the region of the universe above the terrestrial sphere. Aristotle included it as a fifth element distinct from the other four, Earth, Water, Air, and Fire. Aether was also called Quintessence (from quinta essentia, "fifth element"). Its Platonic solid, according to Plato, was the Dodecahedron. The word aether in Homeric Greek means "pure, fresh air" or "clear sky", imagined in Greek mythology to be the pure essence where the gods lived and which they breathed, analogous to the aer breathed by mortals (also personified as a deity, Aether, the son of Erebus and Nyx). It corresponds to the concept of akasha in Hindu philosophy.

2. Air which has tangibility and sound for its Gunas (and the skin for its organ).

3. Fire which has shape or colour, tangibility, and sound for its Gunas (and the eye for its organ).

4. Water that has flavour, shape, tangibility, and sound for its Gunas (and the tongue for its organ).

5. Earth has all preceding Gunas, plus its own peculiar Guna of smell (and the nose for its organ).

\section{SAMKHYA PHILOSOPHY}

In Samkhya philosophy a Guna is one of three "tendencies": tamas, sattwa, and rajas. These categories have become a common means of categorizing behavior and natural phenomena in Hindu philosophy, and also in Ayurvedic medicine, as a system to assess conditions and diets. Guna is the tendency of the mind and not the state. For instance, Sattwa guna is that force which tends to bring the mind to purity but is not purity itself. Similarly Rajas is that force which tends to bring the mind to perform some action but is not action itself. The three words satvic, rajasic, and tamasic are used to describe the behaviour of objects in the universe. Every living creature can have any of the three tendencies satvic, rajasic, and tamasic.( Sri Aurobindo, 1942).

Sattwa (originally "being, existence, entity") has been translated to mean balance, order, or purity. This typically implies that a person with more of Sattwa has a positive or even orderly state of mind. Such a person is psychologically kind, calm, alert and thoughtful.. Indologist Georg Feuerstein translates sattwa as "lucidity". In Hindu philosophy, sattwa (Sanskrit for "pure", sometimes transliterated satva, sattwa, or other spellings) is the highest of the three gunas. Any object or creature can be called satvic if it has no source in evil and can cause only good to the world. Other words are rajasic and tamasic, which are used to denote things that are not satvic. In the Hindu Veda, Sattwa can also means existence, being, goodness, power, .. etc. 


\section{Sattwa, Rajas \& Tamas (SRT) Factors in Depression}

For an object or food to be satvic, it must be uncontaminated and should not spread evil or disease in the world. On the contrary its presence must purify the surroundings. Thus when an individual consumes such a food, he must feel that he is eating pure food. The food should be healthy, nutritious and clean. It should also not weaken the power or equilibrium of mind. This idea disallows aphrodisiac or other drugs and intoxicants that can affect the mind. It also disallows food or objects obtained after killing or causing pain to a creature. This is because the object would then have source in an evil act. It also excludes stale and pungent-smelling food.

A person or creature can be called satvic if the creature has predominantly satvic tendencies. A satvic individual always works for the welfare of the world. He is always hardworking, alert and lives life moderately. He leads a chaste life. He eats moderately. He speaks the truth and is bold. He never uses vulgar or insulting language. He does not feel jealous nor is he affected by greed and selfishness. He does not cheat or mislead anyone. He does not even allow any evil tendencies to enter his mind. He has good memory and concentration. He also has keen interest in improving his spiritual knowledge, and spends time worshiping god or meditating. In the extreme state he may even perform penance or uninterrupted meditation. A satvic individual can be recognized if his mind, speech and actions synchronize. Manasa, vacha, karmana are the three Sanskrit words used to describe such a state. The satvic type can be again classified into seven subtypes (Rao et al, 1990) :

- Brahma typecomprise purity, truth, self control, proper discrimination and knowledge, good understanding, power of exposition and repartee, possessing good memory, and lack of desire, ander, greed, conceit, delusion, envyand intolerence. The person treats others with equality.

- Rishi type comprises devotion to rituals, studies of scriptures, sacrifical offering, celebacy, hospitality, ingenuity, eloquence, understanding and good memoty. Such a person is devoid of vanity, conciet, attachment, hatred, delusion, greed and anger.

- Indra type comprices of mind that commands power, speech, and conducts sacrifice. He is brave and energetic, valiant, blameless, and farsighted. He is always in pursuit of virtue, wealth and sense pleasure.

- Yama type is a person of propriety who does the right thing and is blameless, conscientious and possesses good memory. He is free from attachment to passion, hatred and delusion.

- Varuna type of person is valient, corageous, clean and despises untidiness. He is devouted to sacrifices, is interested in aquatic games and uncomplicated work. He is given to the right way of anger and favour.

- Kubera typeof person commands status, respect, luxuary and plenty of associates. He is after virtues, wealth and desires, is clean and enjoys recreations. Both his anger and favour are reasonable. 


\section{Sattwa, Rajas \& Tamas (SRT) Factors in Depression}

- Gandharva type of person is fond of dance, music, flattery, and is adept in poetry, history and epics; he is addicted to perfumes,cosmetics, garlands, fine garments, women and recreation and is free from envy.

Some of the people considered by Indians to be satvic are:

Holy men and bhaktas like Tulsidas, Tyagaraja, Tukaram, ancient rishis like Vashishta, Kashyapa, modern day sages like Ramana, Aurobindo, modern day leaders like Mahatma Gandhi, Rajagopalachari, divine beings in heavens.

Some objects that are considered satvic are:

Flowers, fruits, and food that are allowed as offerings to God, neem tree, the milk of a cow which has grown in good surroundings, is healthy and has been obtained after the calf of the cow has been fed well. In cases when the cow has been ill treated, it becomes sinful or evil to drink such milk. It must be remembered that the cow is sacred for the Hindus

Sentient foods or sattvic foods are foods which, according to Yoga, lead to clarity and equanimity of mind.Such foods include: water, fruit, cereal, bread, most vegetables, beans, nuts, grains, milk and milk derivatives (cheese, butter, cream, yogurt), honey.

Rajas (originally "atmosphere, air, firmament") leads one to activity. This type of activity is explained by the term Yogakshem. Yogakshem is composed of two words: Yoga and Kshem. Yoga in the present context is acquiring something that one does not have. Kshem means losing something that one already has. Rajas is the force that creates desires for acquiring new things and fears for losing something that one has. These desires and fears lead one to activity. Feuerstein translates rajas as "dynamism". In Hinduism, rajas, or rajo-guna is the quality of activity. If a person or thing tends to be extremely active, excitable, or passionate, that person or thing is said to have a preponderance of rajas. It is contrasted with the quality of tamas, which is the quality of inactivity, darkness, and laziness, and with sattwa, which is the quality of purity, clarity, and healthy calmness.

Rajas is described in the Samkhya philosophy, One of the Six Indian Schools of Philosophy. It is a force which promotes one or more of the following: (1) action; (2) change, mutation; (3) passion, excitement; (4) birth, creation, generation. Note that passion is a feeling (often) associated with the act of generating something new. Rajas is viewed as being more positive than tamas, and less positive than sattwa; except, perhaps, for one who has "transcended the gunas". The (eventual) fruit of rajas is pain, even though the immediate effect of rajas is pursuit of pleasure. Persons who are "movers and shakers" may be characterized as rajasic. Rajas provides raw get-up-and-go power: it propels "go-getters". Consuming food too quickly is rajasic. 


\section{Sattwa, Rajas \& Tamas (SRT) Factors in Depression}

Stimulant foods, also called mutative foods, mutable foods or rajasic foods, are foods which tend to provoke mental restlessness. Such foods include: coffee, tea, cola drinks, chocolate, hot spices, salt.

Rajas can be again subtyped into the following six types (Rao et al, 1990) :

- Asura type of person has qualities of obstinacy, valour, jealousy, authority, obscurantism, terror, harshness, and self agrandisement.

- Rakshasa type of person is intolerant, is always angry, cruel, gluttonous, fond of mutton, excessively sleepy, lazy and jealous of others.

- Pisacha type of person is voracious eater, easily controlled by women, secretly keeps company with women, is dirty, dislikes cleaniless, cowardly, threatens others, and is given to unusual recreation and food.

- Sarpa type of person is one who is brave when exicited, otherwise timid, is sharp, indolent, arouses fear in others and is fond of food and recreation.

- Preta satwa type type of person is fond of food, miserable in character, jealous, avaracious and lazy.

- Sakuna type of person is passionate, fond of good food, fickle minded, intolerant and generous.

\section{QUOTES FROM BAGVAD GITA}

"O Arjuna, know that rajas is the source of lust and attachment and the producer of desire for sense gratification and sentimental infatuation; that enslaves the embodied consciousness by attachment to fruitive activities." (BG 14:7)

"O Arjuna, when greed, restless exertion with great endeavor for fruitive activities, agitation of the senses, incessant desire for sensual indulgence; when all these arise, rajas predominates." (BG 14:12)

"The result of virtuous activities in sattwa is declared purity, the result in rajas is misery, and the result in tamas is nescience." (BG 14:16)

"Arjuna said: what is it that incites one to commit sinful acts even against one's will as if compelled by force? Lord Krishna said: it is lust which becomes anger arising from rajas; know this lust to be insatiable, extremely sinful and the greatest enemy in this world." (BG 3:36-37)

Tamas (originally "darkness", "obscurity") has been translated to mean "too inactive", negative, lethargic, dull, or slow. Usually it is associated with darkness, delusion, or ignorance. A tamas quality also can imply that a person has a self-destructive or entropic state of mind. That person is constantly pursuing destructive activities. Feuerstein translates tamas as "inertia". In Hinduism and Budhism, Tamas, or tamo-guna, is the lower of the three gunas. It is a force which promotes

(C) The International Journal of Indian Psychology, ISSN 2348-5396 (e)| ISSN: 2349-3429 (p) | 78 


\section{Sattwa, Rajas \& Tamas (SRT) Factors in Depression}

one or more of the following: (1) darkness, (2) death, (3) destruction, (4) ignorance, (5) sloth, (6) resistance. Note that sloth is related to death by analogy, and likewise, ignorance is related to darkness. Tamas is viewed as being more negative than either rajas or sattwa.

Tamas cannot be counteracted by tamas. It might be easier to counteract it by means of rajas (action), and it might be more difficult to jump directly from tamas to sattwa. The result of a life led by tamas is demerit: demotion to a lower life-form. Tamas corresponds to what Buddhists call "delusion", one of the three roots of evil. Also, out of the five hindrances, two of them sloth and doubt - are caused by tamas. Persons who are "couch potatoes" may be characterized as tamasic. Overeating (i.e. gluttony) is tamasic.

Static foods or tamasic foods are foods whose consumption, according to Yoga, lead to a duller, less refined, state of mind, whether or not they are good for the body. Static foods include: meat, fish, eggs, onions, garlic, mushrooms, alcoholic beverages, stale foods.

Tamasic type can agan be subtyped into the following three types (Rao et al, 1990) :

- Pashava type of person is critical, unintelligent, disgusting in behavior and eating, sensual and fond of sleep.

- Matsya type of person is timid, unintelligent, gluttonous, passionate, irritable, fond of travelling, unsteady and fond of water.

- Vanaspatya type of person is lazy, gluttonous and dull.

\section{QUOTES FROM BAGVAD GITA}

"You should know, O Arjuna, tamas as the cause of delusion enslaving all embodied beings born of nescience; by negligence, listlessness and somnolescence." (BG 14:8)

"O Arjuna, nescience, inertness, neglectfulness and also illusion; when these arise tamas predominates." (BG 14:13)

"Succumbing to death in rajas one takes birth among those beings attached to fruitive activities; similarly, dying in tamas, one takes birth from the womb of an animal." (BG 14:15)

\section{NYAYA PHILOSOPHY}

In Nyaya philosophy, twenty-four Gunas are enumerated as properties or characteristics of all created things.

1. rūpa, shape, colour;

2. rasa, savour;

3. gandha, odour;

4. sparśa, tangibility;

5. samkhyā, number;

6. parimāna, dimension; 


\section{Sattwa, Rajas \& Tamas (SRT) Factors in Depression}

7. prthaktva, severalty;

8. samyoga, conjunction;

9. vibhāga, disjunction;

10. paratva, remoteness;

11. aparatva, proximity;

12. gurutva, weight;

13. dravatva, fluidity;

14. sneha, viscidity;

15. shabda, sound;

16. buddhi or jñāna, understanding or knowledge;

17. sukha, pleasure;

18. duhkha, pain;

19. icchā, desire;

20. dvesha, aversion;

21. prayatna, effort;

22. dharma, merit or virtue;

23. adharma, demerit;

24. samskāra, the self-reproductive quality;

\section{THEORIES OF PERSONALITY IN INDIA}

The first reference about the concept of personality is available in the oldest texts called 'Vedas' and 'Upanishads'. According to the 'Veda' and 'Upanishads' the essence of human personality is 'Atman (self), which is the same as the 'Brahman'. Atman' in conjunction with gross and subtle bodies becomes subject to experience of pleasure and pain. Its true nature becomes as if veiled. It becomes engrossed in five types of sheaths (Kosha) and the total personality is called 'Jiva'. These five sheaths are found in the world of non-ego. The first two ('annamaya' and 'pranamaya') form the physical self. The next two 'manomaya' and 'vijnanamaya') form the mental self. The last ('anandamaya') is the spiritual or blissful self (Sharma, 1971). The 'Vedas' and 'Upanishads' also talk about the development of human life and basic elements of human personality.

In later stage when the codes of conduct are regulated in Smriti, the span of life was classified into different stages-'Brahmacharya', 'Grihasta', 'Vanaprastha' and- 'Sanyasa'. In addition, they prescribe the duties that one has to follow in these stages, called 'Purusharthas.' They are 'Dharma' (duty), 'Artha' (material gain), 'Kama' (desire), and 'Moksha' (liberation). These stages and duties are not strictly in a sequence, rather it depends upon the maturity of the mind and the responsibility that one has. These four stages of life are interwoven with the aims of life ultimately result in the development of an ideal personality. 


\section{Sattwa, Rajas \& Tamas (SRT) Factors in Depression}

The study of personality in Buddhism does not deal with complex of postulated entities such as mind, ego, or unconsciousness, but is the congregation of five skandhas (series of events or groups). These are 'rupa', 'vedana', 'samjna' (conceptual knowledge), 'samskara' (coordination) and 'vijnana'. These five are transferred from one birth to the next and these constitute a temporary human identity.

Jainism speaks of personality in the form of 'Lesya'. They are of six types - black, blue, dovegrey, flamining red, pink/yellow and white (Krishnan, 1968). But a scientific theory of personality is developed in Indian medical texts. Ayurveda defines personality in terms of bodily humours. i.e. , 'vata' (wind), pitta' (bile), and 'kapha' (phlegm). There should be equilibrium of these three humours. Depending upon the change in the proportion of these three humours, specific type of personality arises. There is a possibility of seven types - 'vata, pitta, kapha, vatapitta, vata-kapha, pitta-kapha and sannipada'. Ayurveda also has given sixteen types of personality on the basis of 'Guna theory" — 6 "rajas 7 sattwa and 3 "tamas. (Balodhi, 1987).

In the south, a parallel medical school called "Siddha" developed almost during the same time .It also speaks of three humours similar to Ayurveda - 'Vali' (wind), 'azhal' (bi1e), and 'iyain' (phelgm), called 'mukkutram' which has to be in the ration 4:2:1. Somatotyping ('thegaillakkanam : of six kinds — 'vali—azhal, vali—iyam, azhal-iyam, azhal-vali, iyam-vali, iyam-azhal (Somasundaram, 1986).

On physical plane if 'vata', 'pitta' and 'kapha' constitute the personality, a psychological significance is attatched to mental attributes, classically known as 'Triguna' or three attributes 'Sattwa', 'Rajas', and 'Tamas'.

Major contributors of this theory are 'Sankhya' and 'Ayurveda' schools. In following lines a detailed account is provided as to show how Indian theories of personality are viewed upon. Human personality, according to sankhya is the product of conjunction and interaction of a pure spirit (purusha) and matter (prakriti). The emprical self (jiva) is the composite of spirit and matter. These two are interdependent. The physical and mental organism attatched to purusha is a manifestation of 'prakriti and without it the 'purusha' is inactive, as the organism is lifeless without it. On the whole personality has two mutually interdependent constituent — spirit ('purusha') and psychophysical apparatus. The psychophysical apparatus is called 'karana' which is the organ and functions. So, personality in sankhya' school is viewed as a result of the interaction between prakriti (matter) and purusha (self).

In their interaction, the first manifestation occurs in the form of mahat (conciousness), which confines to one individualism (ego) or ahamkara. This ahamkara further manifests in 'manas' (mind); 5 gross elements and 5 subtle elements due to divergent potentiality of 'Triguna. These Trigunas thus reflect the temperamental aspect of an individual. 


\section{Sattwa, Rajas \& Tamas (SRT) Factors in Depression}

Triguna' are mutually dependent and by virtue of one's dominance over the rest of the two, the personality typing sets in with different temperament. All the things are composed of these three 'Gunas'. "Gunas” are not merely distinct but in some measure are antagonistic in their nature. But these 'gunas' are never separate, and function as one like the lamp flame which is the result of the co operation of the wick, oil and fire.

These 'gunas' are in a state of perfect equilibrium in prakriti' But even in this state of equilibrium they are continuously changing into one another. So long as the equilibrium is not disturbed, the changes produce no result, but as soon as the proportion of their interaction increases and the equilibrium is disturbed, the evolution takes place. On earth no two individuals are alike in their temperament and personality. Individuals differ in their cognitive, affective and conative aspects according to the interplay of 'Triguna'. According to the predominance of any one of them, the individual is either 'Sattvic' , 'Rajasic' or 'Tamasic' (Balodhi \& Singh, 1985).

'Prakriti' with its inevitable 'Triguna' is the primal matrix of the entire cosmos. The 'Triguna' or the three interwined strands are both the constituent and changing conditions of nature (Padmasrinivasan, 1990).

A detailed comprehensive psychological explanation on 'Triguna' is also found in 'Bhagvathgita'. Lord Krishna declares the three modes; goodness, passion and dullness, born of nature bind down in the body (Gita $14 \mathrm{~V}$ ). This cant be explained in terms of the 'mans' psychic make-up determined by the predominance of any one of the three Gunas.

Aurabindo (1972) had interpreted 'Sattwa 'Rajas and 'Tamas' in more psychological fashion. For him 'Rajas stands mid way between the two polarities of 'Sattwa' and Tamas' supplying energy to both, like a kinetic force. It is born of natures thirst for an unpossessed satisfaction.

\section{METHODOLOGY}

Aim

- To study the pattern of 'Sattwa', 'Rajas' and 'Tamas' factors in patients diagnosed with mild to moderate depression .

\section{Objective}

1. To find out the pattern of SRT factors (sattwa, rajas, tamas) among individuals with mild to moderate depression.

2. To find out SRT factors among normals.

3. To compare the pattern of SRT factors between the cases of mild to moderate depression and normals. 


\section{Sattwa, Rajas \& Tamas (SRT) Factors in Depression}

\section{Tools Used}

\section{SRT factor-Inventory (Marutham, 1992)}

The purpose of this inventory is to understand the disposition of 'Triguna' factors in individuals and is applied on the adult population. It consists of 120 items to be marked on a 4 point scale ranging from never true to always true, The 'sattwa', 'rajas' and 'tamas' factors are based on the 'Triguna' theory as it appears in the Sankhya Karika, Sarva Sidhanta Sangraha and Bagvathgita. The inventory requires 1 to 2 hours for administration and yields 3 scores. One each for each factor. Four point scale is preferred to odd number scale in order to control the mid point rating.

\section{Beck’s Depression Inventory (Beck et al., 1961)}

This inventory authored by Aron. T. Beck is designed to measure the presence of depression in adolescents and adults. It produces a single score indicating the intensity of a depressive episode. It is a 21- item test presented in multiple choice format which purports to measure presence of degree of depression in adolescents and adults. Each of the 21 items attempts to assess a specific symptom or attitude which is consistent with the description of depression as available in the literature.

\section{Total score Levels of Depression are}

Score 05 - 09: These ups and downs are considered normal,

Score 10 - 18: Mild to moderate depression,

Score 19 - 29: Moderate to severe depression,

Score 30 - 63: severe depression,

Score Below 4: Possible denial of depression, faking good; this is below usual scores for normals.

Score over 40: This is significantly above even severely depressed persons, suggesting possible exaggeration of depression; possibly characteristic of histrionic or borderline personality disorders. Significant levels of depression are still possible (Groth-Marnat, 1990).

\section{General Health Questionnaire (GHQ; Goldberg and Hiller, 1979)}

The general health questionnaire (GHQ) is a measure of current mental health and since its development by Goldberg in the 1970s it has been extensively used in different settings and different cultures. The questionnaire was originally developed as a 60 -item instrument but at present a range of shortened versions of the questionnaire including the GHQ-30, the GHQ-28 the GHQ-20, and GHQ-12 is available. The scale asks whether the respondent has experienced a particular symptom or behavior recently. Each item is rated on a four-point scale (less than usual, no more than usual, rather more than usual or much more than usual). When using the GHQ-12 it gives a total score of 36 or based on the selected scoring methods. The most common scoring methods are bi- modal (0-0-1-1) and Likert scoring styles (0-1-2-3). The GHQ-12 is a brief, simple, and easy to complete scale and its application in research settings as a screening tool is well documented. There is evidence that the GHQ-12 is a consistent and reliable instrument when used in general population samples. 


\section{Sattwa, Rajas \& Tamas (SRT) Factors in Depression}

\section{Sample}

1. A sample of 20 cases was selected from the different adult psychiatric units at NIMHANS.

2. A sample of 20 cases of normals was selected from the general population.

\section{Inclusion Criteria}

1. Age group between 18 to 65 years.

2. Both males and females were included.

3. Diagnostic categories that were included are mild to moderate depressed patients as per ICD-10 criteria.

4. Education $7 \mathrm{th}^{\text {th }}$ standard and above.

5. Both English and Hindi comprehending subjects were included.

\section{Exclusion Criteria}

Patients having a history of any organic conditions, protracted physical illness and psychotic illness were excluded from the study.

\section{Procedure}

1. SRT inventory was administered to the selected mild to moderate depressed patients and the 'Triguna' scores were obtained.

2. Becks depression inventory (BDI) was administered to rate the level of depression in each case.

3. GHQ was administered to the normal group. Only those who obtained scores below the prescribed cut-off points were included in the normal sample.

\section{Data Analysis}

1. Descriptive statistics such as percentage, means and standard deviation were computed for the socio demographic variables such as age, sex, education and marital status. Using the statistical package for social sciences (SPSS), 't' tests and correlation was carried out.

2. To find out which factors among the SRT-factors is predominant among subjects diagnosed with mild to moderate depression, 't-test' was carried out between 'Sattwa' and 'Rajas', 'Sattwa' and 'Tamas' and 'Rajas' and 'Tamas' factors and the significance of the difference between the means was estimated.

3. To find out which factors among the SRT-factors is predominant among normals, 't-test', was undertaken between 'Sattwa' and 'rajas', 'Sattwa' and 'Tamas' and 'Rajas' and 'Tamas' factors and the significance of the difference between the means was estimated.

4. To compare the mean scores of the two groups on the independent variables of 'sattwa', 'rajas' and 'tamas', and to estimate the significance of difference of the means between the experimental group and the control group 't-test' was carried out. 


\section{SUMMARY OF RESULTS}

The aim of the present study was to find out the nature of personality based on the personality factors as delineated in the Triguna theory from Indian philosophy. The objective was to find out the SRT factors (sattwa, rajas, tamas) among individuals with mild to moderate depression and the normal population and to study and compare the differences observed between the two groups. For this purpose the SRT Inventory developed and standardized by Marutham et al (1992) was used. A sample or 20 patients diagnosed with mild to moderate depression (ICD-10 criteria for unipolar depression) was selected from various adult psychiatric units and out patient department of NIMHANS after screening them for current level of depression using the Beck's Depression Inventory. A sample of 20 cases of normals was randomly selected from the general population using GHQ as the screening instrument. The age group included was 18-65 years with minimum educational qualification of $7^{\text {th }}$ standard and with ability to read and comprehend English. Patients having a history of any organic conditions, protracted physical illness and psychotic illness were excluded from the study. Purposive random sampling was used to collect the sample. The SRT inventory was administered to the selected mild to moderate depressed patients and the sample of normals, and the 'Triguna' scores were obtained. Statistical measures like percentages, mean, standard deviation, t-test and correlations were employed to undertake a with-in group and between group analyses of the data obtained.

Results obtained show the following:

- The clinical group is higher on Rajas factor than Sattwa factor followed by Tamas factor.

- In the clinical population the difference between Rajas and Tamas factor is not statistically significant but both Rajas and Sattwa factors are significantly higher than Tamas factor.

- In the control group Sattwa factor is higher than the Rajas factor followed by Tamas factor. All the differences are statistically significant.

- In both the clinical group and the control group Sattwa and Rajas factors are significantly higher than Tamas factor.

- On the independent variable of 'Sattwa' the control group is significantly higher in comparison with the clinical group.

- On the independent variable of 'Rajas' the clinical group is higher than the control group though it is not statistically significant.

- On the independent variable of Tamas factor the clinical group is significantly higher in comparison with the control group.

- The males in the control group are significantly higher on the 'Sattwa' factor in comparison with the males in the clinical group.

- The females of the control group are significantly higher on the 'Sattwa' factor in comparison with the females of the clinical group.

- The males in the clinical group are significantly higher on the 'Rajas' factor in comparison with the males in the control group.

(C) The International Journal of Indian Psychology, ISSN 2348-5396 (e)| ISSN: 2349-3429 (p) | 85 


\section{Sattwa, Rajas \& Tamas (SRT) Factors in Depression}

- The females of the clinical group are higher on 'Rajas' factor in comparison with females in the control group, the difference is not statically significant.

- The males in the clinical group are significantly higher on 'Tamas' factor in comparison with the males in the control group.

- The females of the clinical group are higher on 'Tamas' factor in comparison with females in the control group, the difference is not statically significant.

- The married individuals in the clinical group are significantly lower on the 'Sattwa' factor in comparison with the married individuals in the control group.

- The married individuals in the clinical group is significantly higher on the 'Rajas' factor in comparison with the married individuals in the control group.

- The married individuals in the clinical group are higher on the 'Tamas' factor in comparison with the married individuals in the control group, but the difference is not statistically significant.

- The unmarried individuals in the clinical group are significantly lower on the 'Sattwa' factor in comparison with the unmarried individuals in the control group.

- The unmarried individuals in the clinical group are marginally lower on the 'Rajas' factor in comparison with the unmarried individuals in the control group, but it is statistically insignificant.

- The unmarried individuals in the clinical group are higher on the 'Tamas' factor in comparison with the unmarried individuals in the control group, but it is statistically insignificant.

- There is no significant correlation between the Sattwa factor, Rajas factor and Tamas factor and the BDI scores and also among themselves.

\section{IMPLICATIONS}

Contrary to the popular conception that Tamas is the root cause of most of the mental agonies experienced by the human beings. This study concludes that Tamas by itself may not be the cause of depression but a combination of Rajas and Tamas with Rajas predominating seems to be the source of depression. "Gita" says that anxiety for the fruits of actions is an unprofitable channel of vital human energy. Desire, anger and greed that leads to enterprise restlessness and endless longing for things not yet acquired and profits not yet gained is traced to be the source of individuals excessive attachments or affections, which is a basic characteristic of Rajasic attribute which finally leads to "Dukha".

\section{REFERENCES}

Adler, A. (1927). The practice and theory of individual psychology. Harcourt, New York: C. F. Hall \& Lindzey (1957). Theories of Personality. John Wiley \& sons. New York. 185-186.

Alford, B.A. \& Gerrity, D.M. (1995). The specificity of sociotrophy-autonomy personality dimensions to depression vs anxiety. Journal of Clinical Psychology, 51, 190-195. 


\section{Sattwa, Rajas \& Tamas (SRT) Factors in Depression}

Allport, G.W. (1937). Personality. C.F. Ledford B. J., (1964). Interpreting personality theories. Harper and Row Publishers. New York.

Balodhi, J.P. \& Singh, J. (1985). Contribution of Indian thoughts towards understanding personality dynamics - Sankhya views, Vagbhata. An International Journal of Ayurveda. $1,25-27$.

Bandura, A. (1969). Principle of Behaviour modification. Holt Richart \& Winston, New York, U.S.A.

Blash Field, R., Noyers, R., Reich, J. \& Woodman, C. (1994). Personality disorder traits in Generalised anxiety and Panic disorder patients. Comprehensive Psychiatry, 35, 329-334.

Boyce , P., Hickie, I., Parker, G., Mitchell, P., Wilhelm, K., \& Brodaty, H. (1992), Interpersonal sensitivity and the one-year outcome of a depressive episode, Australian \& New Zealand Journal of Psychiatry, vol. 26,no. 2, pp. 156-161.

Brand, H. (1954). The study of personality. John Wiley and Sons. New York.

Cattell, R. B. (1950). Personality: A systematic, theoretical and factual study. New York: McGraw and Hill.

Clark, L.A., Watson, D. \& Mineka, S. (1994). Temperament, Personality and the mood and anxiety disorders. Journal of Abnormal Psychology, 103, 103-116.

Dollard, J., \& Miller, N. E. (1950). Personality and psychotherapy: An analysis in terms of learning, thinking and culture. New York: McGraw and Hill.

Eysenck, H.J. (1960). Structure of human personality. Metheum, London.

Freud, S. (1947). An outline of psychoanalysis. Norton, New York.

Gamez, W., Watson, D. \& Doebbeling, B.N. (2006). Abnormal personality and the mood and anxiety disorders: Implications for structural models of anxiety and depression. Journal of Anxiety Disorder. 13,

Gasperini, M., Battaglia, M., Diaferia, G. \& Bellodi, L. (1990). Personality features related to Generalized Anxiety Disorders. Comprehensive Psychiatry, 31, 363-368.

Goldberg, D.P. and Hitteer, V.F. (1979). A scaled version of the General Health Questionnaire. Psychological Medicine, 9, 139. 191-197.

Gupta, S.C. (1997). Bhagavad Geeta: An epitome of psychotherapeutic concepts. Indian Journal of Psychiatry. 24, 42-45.

Hall, C. S. \& Lindzey, G. (1957). Theories of personality. John Wiley \& Sons. Inc. New York.

Hirschfeld, R. M., Klerman, G.L., Clayton, P.J. \& Keller M.B (1983). Personality and Depression. Archives of General Psychiatry. 40. 993-998.

Hoffart-Asie. (1995). Psychoanalytical types and anxiety and depressive disorders. European Journal of Psychiatry, 9, 133-138.

Jung, C.G. (1928). Contributions of Analytical Psychology. Harcourt. New York.

Kagan, J. (1971). Personality development. Harcourt Brace Jounavich, Inc, New York.

Kapur M., Hirisave, U. \& Reddy, M.V. (1997). Study of Infantile Temperament: An Indian perspective. Indian Journal of Clinical Psychology, 24, 171-177. 


\section{Sattwa, Rajas \& Tamas (SRT) Factors in Depression}

Kretchsmer, E. (1925). Physique and character. Harcourt New York. Cf. Hall, C. S. \& Lindzey, G. (1957). Theories of personality. John Wiley \& Sons. Inc. New York.

Krishnamurthy, N. (1961). The Sankhya conception of personality. Transactions December. All India Institute of Mental Health. Bangalore.

Krishnamurthy. U, Swarajya, L. \& Parameshwaran, E. G. (1971). Construction of a Personality Inventory Based on Doctrine of three Gunas. Research Bulletin, 6, Osmania University, Hyderabad.

Krishnan, B. (1968). Studies in psychology. University of Mysore, Mysore.

Laxmi, A. J. (1966). An enquiry into temperamental and constitutional traits according to Indian thought, Unpublished DM \& SP Dissertation. AIIMH, Bangalore.

Laxmi, A. J., Murthy, H. N. \& Nagalakshmi, S.V. (1975). Rajas and Tamas in Psychological disturbance. Indian Journal of Clinical Psychology, 2, 135.

Maier.W., Lichtermann, D., Minges, J. \& Heun, R. (1992). Personality traits in subjects at risk for unipolar major depression: A family study perspective. Journal of Affective Disorder. 24, 153-63.

Marutham, P., Balodhi, J.P. \& Mishra, H (1992). Sattva, Rajas and Tamas factor among college students. unpublished dissertation submitted to the Bangalore University. Department of Clinical Psychology, NIMHANS.

Maslow, A.H. (1954). Motivation and personality. Hasper. New York.

McCrae, R. R., \& Costa, P. T., Jr. (1987). Validation of five factor model of personality across instruments and observers. Journal of Personality and Social Psychology, 52, 81-90.

Mohan, V. \& Sandhu, S. (1968). Development of scale of measure sattwic, rajasic \& tamasic Gunas. Journal of Indian Academy of Applied Psychology, 12, 46-52.

National Seminar on Indian Personality Constructs - Models and Assessment (1989). Banaras Hindu University.

Ormel .J, Oldehinkel A.J,Volleberg W (2004). Vulnerability before, during and after a Major Depressive episode. Archives General Psychiatry, 61, 990-996

Parikh, B.A. (1971). Personality in Indian Psychology. In Ramnath’s Indian Psychology. Kedarnath Ramanath. India.

Peselow, E. D., Sanfilipo, M. P., Fieve, R. R. \& Gulbenkian, G. (1994). Personality traits during depression and after clinical recovery. The British Journal of Psychiatry, 164, 349-354.

Rao, R. (1962). Development of Psychological Thought in India. Kavalaya, Mysore.

Rogers, C.R. (1947). Some observations on the organization of personality. American Psychologist, 2, 358-368.

Sastri, S. P. P \& Sukia, S. H. (1942). The Nyayadrashana of Gutam Muni with the Bhashya of Vatsayana. Jaya Krishna Das \& Hari Das Gupta, Banaras.

Sheldon, W. H. (1940). The varieties of human physique: An introduction to constitutional psychology. New York: Harper.

Singh, R. (1971). An Inventory from Mahabaratha. Indian Journal of Psychiatry, 13, 149-161.

Sivananda, S. S. (1988). All about Hinduism- The divine life society. Uttar Pradesh. 


\section{Sattwa, Rajas \& Tamas (SRT) Factors in Depression}

Skinner, B. F. (1984). Selection by consequences. Behavioral and Brain Sciences, 7, 477-510.

Somasundaram, O., Jayaramakrishnan, T. \& Kumar, S. M. (1986). Psychiatry in Sidda (Tamil) system of medicine. Indian Journal of Psychological Medicine. 9. 38-45

Sri Aurobindo. Essays on the Gita. (1976). Sri Aurobindo Ashram. Pondicherry.

Sri Mat Bhagavath Gita (1960). Gita Press, Gorakhpur.

Srinivasan, P. (1990). Tamas or Darkness. Vedic path, 24, 34-66.

Srinivasan, R. (1986). Stress and coping behavior in college students. unpublished dissertation submitted to the Department of clinical psychology NIMHANS, Bangalore.

Stanley, B. \& Wilson, S.T. (2006). Heightened subjective experience of depression in borderline personality disorder. Journal of Personality Disorder. 20, 307-318.

Tripathi, I. \& Pandey, R. (2005). Mansik prakriti of cancer patients: an empirical study. Ayurveda and Mental Health.

Wig, N. N. (1999). Mental health and spiritual values: A view from the East. International Review of Psychiatry, 11, 92 - 96.

Yager, J. (1997). Personality Traits Predict Onset and Relapse of Depression. Journal Watch Psychiatry, 701.

Yogendra. (1950). Yoga and Universal Mysticism. Yoga Journal of the Yoga Institute. 4, 10 17.

How to cite this article: A Kumar, J Balodhi (2016), Sattwa, Rajas \& Tamas (SRT) Factors in Depression, International Journal of Indian Psychology, Volume 3, Issue 4, No. 56, ISSN 23485396 (e) | ISSN: 2349-3429 (p), DIP: 18.01.008/20160304, ISBN: 978-1-365-23992-2 